\title{
Effect of a Heart-Targeted Dietary Program on Blood Pressure: Summary Data and a Series of Case Reports
}

\author{
Bell SJ1*, Baker RA² and Marsland ${ }^{3}$ \\ ${ }^{1}$ Chief Science Officer, Nutrient, USA \\ ${ }^{2}$ Quality Control Quality Assurance Nutritionist, Nutrient, USA \\ ${ }^{3}$ Co-Founder and Vice Chairman, Nutrient, USA
}

*Corresponding author: Stacey J Bell, Chief Science Officer, Nutrient, 110

\section{Case Report}

Volume 2 Issue 6

Received Date: October 12, 2018

Published Date: November 15, 2018

DOI: $10.23880 /$ mjccs-16000186

Woodland Avenue Reno, NV 89523, USA, Tel: 617999 6150; Email: stacey.bell@nutrientfoods.com

\section{Abstract}

One-third of the United States adult population has hypertension, of which only about half are well controlled. Besides obesity, the over-consumption of sodium and the lack of potassium in the diet are the major causes of high blood pressure. We explored the effect of a heart-targeted dietary program, consisting of three nutrient-dense foods, which provided nearly $100 \%$ of the daily need for each vitamin and mineral, except sodium and chloride. Over two months, seven hypertensive and obese participants (one was normal weight) followed the dietary program. In exchange for free food and a blood pressure monitoring device, participants provided weekly, self-reported information about blood pressure, body weight, and quality of life indicators. The mean morning blood pressure readings decreased at week 4 , and by week 8 had a better lowering effect than anti-hypertensive of 10-20\%. The heart-targeted dietary program produced more of a lowering effect than the DASH diet (Dietary Approaches to Stop Hypertension), which is the main dietary treatment of hypertension. At the end of the study, systolic blood pressure was 3 to 5 times lower than the DASH diet, and the diastolic pressure was 4 to 6 times lower. Average weight loss was $8 \mathrm{~kg}$, and there was a decrease in 3 Body Mass Index units $\left(\mathrm{kg} / \mathrm{m}^{2}\right)$. Indicators of quality of life improved for summaries of physical function and mental health as a comparison to a healthy population. In addition, other things improved such as having a better overall feeling of wellbeing, having more energy, and eating a better diet. New approaches are needed to lower blood pressure. Drugs take longer to become effective ( 3 months or longer), are more costly than dietary management, and have side effects not seen with a dietary intervention. Compared to individuals without hypertension, those with it have higher annual prescription medication costs ( $\$ 2,371$ vs. $\$ 814)$ and total medical expenditures $(\$ 9,089$ vs. $\$ 4,172)$. The DASH is less effective than the targeted-heart program and recommends foods that are not usually consumed. The heart-targeted dietary program 


\section{Medical Journal of Clinical Trials \& Case Studies}

includes foods that the participants enjoyed, and replaced as their regular meals, rather than being additive. A homecooked meal costs about $\$ 9.31$, with $\$ 4.31$ for the food and $\$ 5.00$ for labor; each nutrient-dense meal costs about $\$ 2.75$ per serving. The heart-targeted dietary program may offer a more effective, less expensive, faster approach to treating hypertension than either pharmaceuticals or the DASH diet.

Key words: Diet; Blood Pressure; Nutrients; Heart Health

Abbreviations: CVD: Cardiovascular Disease; DV: Daily Value; BPM: Beats Per Minute; ARB: Angiotensin Receptor Blocker.

\section{Introduction}

The Centers for Disease Control and Prevention states that high blood pressure is a common and dangerous condition. About 1 of 3 U.S. adults-or about 75 million people-have high blood pressure. This common condition increases the risk for heart disease and stroke, which are two of the leading causes of death for Americans [1]. Anti-hypertensive drugs are effective and lower blood pressure between $10 \%$ and $20 \%$, but take at least three months to be effective [2]. Compared to individuals without hypertension, those with it have higher annual prescription medication costs $(\$ 2,371$ vs. $\$ 814)$ and total medical expenditures $(\$ 9,089$ vs. $\$ 4,172)$ [3]. Medications used to treat hypertension have side effects such as tiredness, gastrointestinal issues, and low libido [4]. Regardless of the cost and side effect, treating hypertension with pharmaceuticals isn't working because half of those prescribed drugs are not controlled [5].

Lifestyle changes like eating a low-sodium diet, exercising, and not smoking are recommended first for treatment [6]. Of these, diet is the best non-pharmacologic way to help control high blood pressure. Most clinicians prescribe the DASH diet (Dietary Approaches to Stop Hypertension). But, a meta-analysis shows its impact on blood pressure lowering over 2-26 weeks is minimal about $7 \mathrm{mmHg}$ of systolic and $4 \mathrm{mmHg}$ for diastolic [7] More problematic is that no one eats foods recommended in the DASH diet [8]. Americans consume sub-optimal amounts of fruit, vegetables, whole grains, and low-fat dairy foods - all of which are recommended. In addition, most people eat too much of the things that are limited by the DASH diet - salt, sugar, and saturated fat. A homecooked meal, similar to what is required for the DASH diet, costs about $\$ 9.31$, with $\$ 4.31$ for the food and $\$ 5.00$ for labor; each nutrient-dense meal costs about $\$ 2.75$ per serving $[9,10]$.

Sodium, the main dietary driver of hypertension, is over-consumed by all Americans starting at one year of age [8]. Most dietary sodium comes from processed foods like fast-food burgers and mixed meat dishes, pizza, and rice and noodle dishes. New thinking shows that potassium intake, represented by a potassium: sodium of greater than or equal to one, is more predictive of hypertension and cardiovascular disease (CVD) than either sodium or potassium intake alone [11-13]. Only one-tenth of the population has an optimal potassium: sodium [13]. Adding three small boxes of raisins, which are rich in potassium, was enough to significantly lower blood pressure [14]. A low intake of omega-3 fatty acids also contributes to lower high blood pressure [15].

The diet that Americans are eating will never improve management of hypertension, let alone reverse it. It is high in sodium and low in potassium. New dietary strategies are needed. We describe the use of a hearttargeted dietary program in hypertensive, obese subjects. The foods are not only rich in potassium and omega-3 fatty acids, but also low in sodium. Moreover, two previous studies showed these foods produced significant weight loss, which can also contribute to blood pressure lowering $[16,17]$. Weight loss of as little as $5 \%$ has been shown to produce significant reductions in both systolic and diastolic blood pressure readings [18]. The combination of providing nutrients that target blood pressure lowering and weight loss offer a novel, nonpharmacologic approach to the management of hypertension.

\section{Methods}

\section{Subjects}

Participants were recruited through Facebook ads and word-of-mouth from Nutrient's customer base, hereafter 


\section{Medical Journal of Clinical Trials \& Case Studies}

referred to as The Company (www.nutrientfoods.com). All had hypertension confirmed by a healthcare professional and, all but one, were classified as obese. Each participant signed a consent form.

\section{Dietary Intervention}

For two months, subjects followed a heart-targeted program that consisted of two nutrient-dense foods and one nutrient-dense bar, provided at no charge by The Company. Each meal contained $35 \%$ of the Daily Value (DV) for every vitamin and mineral, except sodium and chloride. The bars had 25\% DV for these nutrients. Products are low in sodium with an average of about 300 mg per serving. All foods had a potassium: sodium of greater than one. Only 7/24 nutrient-dense foods exceed $20 \%$ of the DV for sodium, and since each serving is one meal, this is a low amount. The Company offers a variety of nutrient-dense foods like shakes, sauces with noodles or rice, and hot and cold cereals. The three Company meals provided participants with $95 \%$ of all essential nutrients including potassium, protein, and omega-3 fatty acids daily. Subjects were told to consume another meal based on the DASH diet.

\section{Blood Pressure Monitor and Standards for Blood Pressure and Heart Rate}

All participants were provided the same blood pressure monitor, Medline MDS4001, Mundelein, IL 60060 . The blood pressure readings are accurate to \pm 3 $\mathrm{mmHg}$. Blood pressure and resting heart rate readings were obtained weekly at two times during the day - upon waking up in the morning and before bed. Normal blood pressure is $120 / 80 \mathrm{mmHg}$ and heart rate is $60-100$ beats per minute (BPM) [1,19].

\section{Quality of Life Questions}

The participants completed SF-12 ${ }^{\circledR}$ quality of life questionnaire from OptumInsight Life Sciences, Inc., Johnston, Rhode Island. This tool has been used in patients with hypertension [20]. The SF-12 form was completed at the beginning, at week 4 , and at week 8 . Summary scores for physical health and mental health of the participants are compared to the general population, matched for age and gender. This information is presented as the percentage of the subjects above or below a healthy population.
Each week, participants rated a series of quality of questions using a scale of one to five, with five being the best. Questions probed sleep, energy, mood, generally how they felt, passion, gastrointestinal function, fullness, appearance, and diet quality of foods consumed that were not provided by the Company.

\section{Classification of Weight and Waist Circumference}

Classification of being overweight or obese using Body Mass Index (BMI) $\mathrm{kg} / \mathrm{m}^{2}$ and normal or abnormal waist circumference was based on the National Heart, Lung, and Blood Institute of the National Institutes of Health [21]. Being both overweight/obese and having a large waist circumference increases the risk of type 2 diabetes, hypertension, and heart disease. For males, normal waist circumference is less than or equal to $102 \mathrm{~cm}$, and for females, it is less than or equal to $88 \mathrm{~cm}$.

\section{Study Design}

The study lasted eight weeks and was prospective. Each participant was provided foods from The Company's heart-targeted program and the identical blood pressure monitoring device at no charge. Data collection forms were self reported, completed weekly, and submitted to The Company electronically. At least weekly, The Company offered online question and answer sessions for the participants.

\section{Statistics}

All data are presented as means \pm standard deviations.

\section{Results for all Subjects}

All but one of the seven participants completed the 8week study, and most consumed the two nutrient-rich meals and one bar daily. One dropped out at week 6 due to gastroparesis. Baseline demographics are presented in Table 1 . The average age was $56 \pm 4$ years. All but one subject was obese, with a mean BMI of $33 \pm 5 \mathrm{~kg} / \mathrm{m}^{2}$, and mean waist circumferences exceeded normal for males and females. Each subject was hypertensive, with four having Stage 2 and three having either elevated or Stage 1. Of this, five of seven were taking medications to control blood pressure. 


\section{Medical Journal of Clinical Trials \& Case Studies}

\begin{tabular}{|c|c|}
\hline Attribute & Number or Mean \pm standard deviation (S.D.) \\
\hline Gender & $62 \%$ female \\
\hline Age (years) & $56 \pm 4$ \\
\hline Body Mass Index $\left(\mathrm{kg} / \mathrm{m}^{2}\right)$ & $33 \pm 5$ \\
\hline Classification of BMI & $\begin{array}{l}\text { Normal }=1 \\
\text { Overweight }=0 \\
\text { Obese }=6\end{array}$ \\
\hline Waist circumference $(\mathrm{cm})$ & $\begin{array}{l}\text { Males: } 109 \pm 14 \mathrm{~cm}(\text { high risk }>102 \mathrm{~cm}) \\
\text { Females: } 102 \pm 12 \mathrm{~cm}(\text { high risk }>88 \mathrm{~cm})\end{array}$ \\
\hline Co-morbidities & $\begin{array}{l}5 / 7 \text { have metabolic disorders (e.g., diabetes, hypercholesterolemia) } \\
1 / 7 \text { has none } \\
1 / 7 \text { has joint and muscular skeletal pain }\end{array}$ \\
\hline Blood pressure lowering medication use & $5 / 7$ \\
\hline
\end{tabular}

Table 1: Baseline demographic information.

Blood pressure and resting heart rate data are presented in Table 2. Mean morning and evening blood pressure readings decreased between baseline and week 4 , and again at week 8 . At week 8 , the mean morning systolic blood pressure was $125 \pm 13 \mathrm{mmHg}$ and the mean diastolic blood pressure was $70 \pm 8 \mathrm{mmHg}$. Compared to baseline data, this represented a $21 \%$ decrease in systolic blood pressure and a $26 \%$ in diastolic pressure. Similarly, for the evening blood pressure measurements, systolic pressure decreased 15\% and diastolic decreased 19\% at week 8 . The comparison between week 8 and week 4 in the morning and evening were smaller - 9\% lower for both morning systolic and diastolic blood pressure, and $4 \%$ for both measurements in the evening. At the end of the study, systolic blood pressure was 3 to 5 times lower than the DASH diet, and the diastolic pressure was 4 to 6 times lower. Resting heart rates did not change and were normal throughout the study.

\begin{tabular}{|c|c|c|c|}
\hline Time & Baseline & Week 4 & Week 8 \\
\hline Morning & & & $125 \pm 13 / 70 \pm 8^{*}$ \\
\hline Blood pressure (mm Hg) & $158 \pm 28 / 94 \pm 13$ & $136 \pm 24 / 77 \pm 7$ & $65 \pm 5$ \\
\hline Heart rate (BPM+) & $74 \pm 14$ & $69 \pm 11$ & \\
\hline Evening & & & $127 \pm 13 / 72 \pm 10^{\wedge}$ \\
\hline Blood pressure (mm Hg) & $149 \pm 24 / 88 \pm 6$ & $132 \pm 16 / 75 \pm 9$ & $67 \pm 6$ \\
\hline Heart rate (BPM+) & $74 \pm 16$ & $73 \pm 11$ & .
\end{tabular}

*Compared to baseline, this was a $21 \%$ decrease in systolic blood pressure and a $26 \%$ decrease in diastolic. Compared to week 4, this was a 9\% decrease for both systolic and diastolic blood pressure.

+ Beats per minute

${ }^{\wedge}$ Compared to baseline, this was a $15 \%$ decrease in systolic blood pressure and a $19 \%$ decrease in diastolic. Compared to week 4 , this was a $4 \%$ decrease for both systolic and diastolic blood pressure.

Table 2: Blood pressure and resting heart rate changes over two months.

Mean body weight decreased $8 \mathrm{~kg}$ over 8 weeks, representing an $8 \%$ weight loss (Table 3). BMI units decreased $3 \mathrm{~kg} / \mathrm{m}^{2}$ during the study. Males and females experienced reductions in waist circumferences: men by 3 $\mathrm{cm}$ at week 4 , and women by $13 \mathrm{~cm}$ at week 8 .

\begin{tabular}{|c|c|c|c|}
\hline & Baseline & Week 4 & Week 8 \\
\hline Body weight $(\mathrm{kg})$ & $96 \pm 19$ & $93 \pm 17$ & $88 \pm 17$ \\
\hline Waist circumference $(\mathrm{cm}):$ males & $109 \pm 14$ & $106 \pm 21$ & 91 \\
\hline Waist circumference $(\mathrm{cm}):$ females & $102 \pm 12$ & $93 \pm 11$ & $89 \pm 12$ \\
\hline Body mass index $\left(\mathrm{kg} / \mathrm{m}^{2}\right)$ & $33 \pm 5$ & $32 \pm 5$ & $30 \pm 8$ \\
\hline
\end{tabular}

Table 3: Change in body weight, waist circumference, and body mass index. 


\section{Medical Journal of Clinical Trials \& Case Studies}

Quality of life for the SF-12 test and for general questions improved over time (Table 4). For the SF-12 test, the summary scores between baseline and week 8 for physical health and mental health improved during the 8week study. For physical health, at baseline, $43 \%$ of the subjects were better than the general population, and at week $8,83 \%$ were above. For mental health, at baseline $29 \%$ were better than the general population, and at the end, $67 \%$ were better. Compared to the general population, the percentage of the subjects below the standard physical and mental component decreased over 8 weeks. The percentage of the participants below the physical standard went from $43 \%$ at baseline to $0 \%$ at week 8; and for the baseline mental standard, $43 \%$ was below, which decreased to $17 \%$ at the end of the study.

\begin{tabular}{|c|c|c|c|}
\hline Time & Baseline & Week 4 & Week 8 \\
\hline \multicolumn{4}{|l|}{ SF-12 test } \\
\hline Physical component summary compared to a healthy population & $\begin{array}{l}-43 \% \text { above } \\
-43 \% \text { below }\end{array}$ & $\begin{array}{l}-71 \% \text { above } \\
-14 \% \text { below }\end{array}$ & $\begin{array}{c}-83 \% \text { above } \\
-0 \% \text { below }\end{array}$ \\
\hline Mental component summary compared to a healthy population & $\begin{array}{l}-29 \% \text { above } \\
-43 \% \text { below }\end{array}$ & $\begin{array}{l}-29 \% \text { above } \\
-43 \% \text { below }\end{array}$ & $\begin{array}{l}-67 \% \text { above } \\
-17 \% \text { below }\end{array}$ \\
\hline \multicolumn{4}{|l|}{ Other measurements* } \\
\hline General feeling of wellbeing & $2.6 \pm 1$ & $3.8 \pm 1.2$ & $4.3 \pm 0.5$ \\
\hline Fullness & $3.0 \pm 0.6$ & $3.6 \pm 0.8$ & $4.2 \pm 0.4$ \\
\hline Moodiness & $3.4 \pm 1.3$ & $3.8 \pm 1.2$ & $4.0 \pm 1.7$ \\
\hline Energy & $3.1 \pm 1.1$ & $4.0 \pm 1.1$ & $4.7 \pm 0.5$ \\
\hline Gastrointestinal symptoms & $3.3 \pm 1.4$ & $3.9 \pm 1.2$ & $4.5 \pm 0.8$ \\
\hline Sleep & $2.7 \pm 1.0$ & $3.9 \pm 1.1$ & $4.0 \pm 0.9$ \\
\hline Appearance (e.g., hair, skin, nails) & $2.9 \pm 0.7$ & $3.6 \pm 0.8$ & $4.2 \pm 0.4$ \\
\hline Diet quality & $3.0 \pm 0.6$ & $4.0 \pm 1.2$ & $4.8 \pm 0.4$ \\
\hline Passion & $1.7 \pm 1.1$ & $3.3 \pm 1.7$ & $4.3 \pm 1.2$ \\
\hline
\end{tabular}

*The scale used was 1 to 5 , with 5 indicating the best state to be in (e.g., best mood, no gastrointestinal symptoms).

Table 4: Changes in quality of life and general feeling of wellbeing.

Each quality of life indicator improved over the study, with the biggest improvements observed for a general feeling of well-being (65\% increase) and in overall diet quality ( $60 \%$ increase). Increases in at least $50 \%$ were observed for energy level and passion.

\section{Discussion for all Subjects}

Diet is the first line to treat hypertension before pharmacologic interventions. We investigated the effect of a heart-targeted dietary program on blood pressure. Hypertensive and obese subjects (one was normal weight) consumed three nutrient-dense meals daily, which provided nearly $100 \%$ of the essential nutrient needs, except sodium and chloride. The decrease in blood pressure observed over 8 weeks from consuming a hearttargeted program was between $15 \%$ and $26 \%$. These findings are as good as or better than anti-hypertensive drugs, which typically achieve a lowering effect of $10 \%$ to $20 \%$ [2]. The pharmaceutical approach comes with higher costs and more side effects than a dietary approach $[3,4]$.
Prescription medication costs for patients with hypertension are nearly three times more than those without it [3]. Even when anti-hypertensive are used, only about $50 \%$ achieve normal blood pressure levels [5].

The heart-targeted dietary program of nutrient-rich foods performed much better than the standard of care the DASH diet [7]. The DASH diet lowers systolic blood pressure by $7 \mathrm{mmHg}$ and diastolic by $4 \mathrm{mmHg}$. In contrast, the heart-targeted program lowered systolic blood pressure between 22 and $33 \mathrm{mmHg}$, and diastolic between 8 and $24 \mathrm{mmHg}$. Besides only producing a modest blood pressure lowering effect, the DASH diet recommends that individuals consume foods that they typically don't eat. The heart-targeted dietary program includes foods that the participants enjoyed, and replaced regular meals with, rather than being additive. A home-cooked meal costs about $\$ 9.31$, with $\$ 4.31$ for the food and $\$ 5.00$ for labor; each nutrient-dense meal costs about $\$ 2.75$ per serving $[9,10]$. 


\section{Medical Journal of Clinical Trials \& Case Studies}

We have shown that a heart-targeted dietary intervention with nutrient-rich foods reduced blood pressure equal to or better than pharmaceuticals and 3 to 6 times better than the DASH diet. Participants lost a significant amount of weight and found the diet was easy to follow. In addition, they felt better and had more energy. We are currently accruing more hypertensive individuals to follow the same dietary protocol to enhance the reliability of these findings. But, these initial data show that the heart-targeted diet may provide a sustainable approach to managing hypertensive individuals and obviate the need for pharmaceuticals.

\section{Individual Case Studies}

\section{TM}

TM is an obese 55-year-old African American woman, who is "on a mission to change her life". She is happily married and has children and grandchildren. TM and her husband run a marketing business and her free time is devoted to her church; she was appointed to Executive Secretary for the bishop. Her blood pressure has been poorly controlled, despite being on blood pressure lowering medications for 30 years. At the start of the study she was taking Carvedilol, a beta-blocker, at two doses: $25 \mathrm{mg}$ b.i.d. and another, $6.25 \mathrm{mg}$, once a day.

After four weeks, TM's blood pressure was lower than her baseline values, and she lost $6 \mathrm{~kg}$ and $9 \mathrm{~cm}$ from her waist. At week 8, her diastolic blood pressure normalized, but her systolic was still elevated. TM remained weight stable and lost another centimeter from her waist circumference. These findings are remarkable because during the 8-week study, TM developed pneumonia and had to be hospitalized, and underwent orthoscopic knee surgery.

\begin{tabular}{|c|c|c|c|}
\hline Time & Baseline & Week 4 & Week 8 \\
\hline Morning & & & \\
\hline Blood pressure (mm Hg) & $209 / 124$ & $128 / 85$ & $135 / 73$ \\
\hline Heart rate (BPM*) & 70 & 55 & 64 \\
\hline Evening & & & \\
\hline Blood pressure (mm Hg) & $154 / 98$ & $131 / 81$ & $137 / 80$ \\
\hline Heart rate (BPM) & 56 & 63 & 66 \\
\hline
\end{tabular}

*Beats per minute

Table 5: Changes in blood pressure and pulse rate for TM.

\section{ME}

ME is a 55-year-old female, who had a hemorrhagic stroke nine years ago causing her to be mostly in a wheelchair and homebound. Previously, she was a manager in a large retail store. She has been married for 16 years and has one daughter and lots of pets. She is highly motivated to reduce her blood pressure, yet realizes that she'll need to remain on medication for life. She stated that she has more energy after starting the program, and even attempted rock climbing.

After four weeks, her blood pressure normalized, while continuing with $40 \mathrm{mg}$ Lisinopril, an ACE inhibitor, and a diuretic (20 mg, yet not specified). Her body weight was stable, yet she was normal weight upon entry into the study; her waist circumference decreased $5 \mathrm{~cm}$ at week 4 . At week 8, her blood pressure continued to be normal and weight and waist circumference were stable.

\begin{tabular}{|c|c|c|c|}
\hline Time & Baseline & Week 4 & Week 8 \\
\hline Morning & & & \\
\hline Blood pressure (mm Hg) & $125 / 85$ & $110 / 69$ & $101 / 69$ \\
\hline Heart rate (BPM $\left.{ }^{*}\right)$ & 98 & 70 & 68 \\
\hline Evening & & & \\
\hline Blood pressure (mm Hg) & $124 / 84$ & $113 / 70$ & $105 / 71$ \\
\hline Heart rate (BPM) & 89 & 75 & 71 \\
\hline
\end{tabular}

*Beats per minute

Table 6: Changes in blood pressure and pulse rate for ME.

\section{GL}

GL is a 62-year-old single, unemployed male with one child. In early 2018, he started driving for Lyft and gained weight due to eating poorly. He has always been athletic, and particularly enjoys boxing. He thought he was in excellent health until he saw a dentist for routine care, and was identified as having Stage 1-2 high blood pressure. Instead of starting on medications to control his blood pressure, he enrolled in this study. He was also classified as Obese, based on his BMI of $30 \mathrm{~kg} / \mathrm{m}^{2}$, and had a waist circumference approaching an unhealthy amount $(99 \mathrm{~cm})$.

After 4 weeks, his blood pressure was normal. In addition, he lost $5 \mathrm{~kg}$ and $8 \mathrm{~cm}$ from his waist circumference. He is now considered to be Overweight, rather than Obese with a BMI of $28.5 \mathrm{~kg} / \mathrm{m}^{2}$. He remarked how lean he now feels. At week 8, his blood pressure remained normal, although it was trending upward. He lost another $1 \mathrm{~kg}$ and his waist circumference did not change. 


\section{Medical Journal of Clinical Trials \& Case Studies}

\begin{tabular}{|c|c|c|c|}
\hline Time & Baseline & Week 4 & Week 8 \\
\hline Morning & & & \\
\hline Blood pressure (mm Hg) & $152 / 98$ & $118 / 76$ & $128 / 78$ \\
\hline Heart rate (BPM*) & 53 & 56 & 56 \\
\hline Evening & & & \\
\hline Blood pressure (mm Hg) & $131 / 87$ & $116 / 67$ & $130 / 80$ \\
\hline Heart rate (BPM) & 71 & 59 & 58 \\
\hline
\end{tabular}

* Beats per minute

Table 7: Changes in blood pressure and pulse rate for GL.

\section{CW}

This 50-year-old African American woman has a lot to live for; she has two sons in their 20s and hopes that she'll be a grandmother soon. Yet, she has a strong family history of CVD, type 2 diabetes, and hypertension. Her blood pressure at the beginning of the study was Stage 1 hypertension, and she was Obese with a BMI of $35 \mathrm{~kg} / \mathrm{m}^{2}$. Daily she takes $10 \mathrm{mg}$ amlodipine, a calcium channel blocker, losartan, $50 \mathrm{mg}$, which is an angiotensin receptor blocker (ARB) and an unspecified diuretic.

At week four, her blood pressure was lower than baseline, but still elevated, especially at night. However, her physician reduced her amlodipine in half and eliminated the diuretic. She lost $3 \mathrm{~kg}$ and $10 \mathrm{~cm}$ from her waist circumference. At week 8, her blood pressure normalized, her weight was stable, and her waist circumference decreased another $10 \mathrm{~cm}$.

\begin{tabular}{|c|c|c|c|}
\hline Time & Baseline & Week 4 & Week 8 \\
\hline Morning & & & \\
\hline Blood pressure (mm Hg) & $135 / 86$ & $118 / 70$ & $119 / 77$ \\
\hline Heart rate (BPM ${ }^{*}$ ) & 79 & 81 & 71 \\
\hline Evening & & & \\
\hline Blood pressure (mm Hg) & $132 / 80$ & $129 / 85$ & $126 / 81$ \\
\hline Heart rate (BPM) & 97 & 83 & 75 \\
\hline
\end{tabular}

*Beats per minute

Table 8: Changes in blood pressure and pulse rate for CW.

\section{AB}

$\mathrm{AB}$ is a 57 -year-old African American woman with Stage 2 hypertension, hypercholesterolemia, and type 2 diabetes. She was Obese based on her BMI of $37 \mathrm{~kg} / \mathrm{m}^{2}$ and had an unhealthy waist circumference of $112 \mathrm{~cm}$. Her pride is her three grown children and five grandchildren. She hopes to reduce some of her blood pressure medication use. Currently she is taking (an unspecified diuretic) $25 \mathrm{mg}$ once a day; amlodipine (calcium channel blocker) $10 \mathrm{mg}$ once a day; and metoprolol tartrate (beta blocker) $100 \mathrm{mg}$ b.i.d.

After four weeks, her blood pressure had not changed, she gained $1 \mathrm{~kg}$, and her waist circumference was reduced by $5 \mathrm{~cm}$. She states that she is full of energy and enjoying the program. At week 8, her blood pressure normalized; she lost $6 \mathrm{~kg}$ and her waist circumference did not change.

\begin{tabular}{|c|c|c|c|}
\hline Time & Baseline & Week 4 & Week 8 \\
\hline Morning & & & \\
\hline Blood pressure (mm Hg) & $178 / 90$ & $144 / 83$ & $129 / 69$ \\
\hline Heart rate (BPM*) & 67 & 84 & 68 \\
\hline Evening & & & \\
\hline Blood pressure (mm Hg) & $140 / 82$ & $137 / 72$ & $123 / 67$ \\
\hline Heart rate (BPM) & 60 & 91 & 64 \\
\hline
\end{tabular}

*Beats per minute

Table 9: Changes in blood pressure and pulse rate for $\mathrm{AB}$.

\section{RS}

RS is a 52-year-old grandmother, who manages a delicatessen and has a busy family life. She is Obese, according to her BMI $\left(34 \mathrm{~kg} / \mathrm{m}^{2}\right)$ and has an unhealthy waist circumference, indicating a very high risk for high blood pressure, type 2 diabetes, and heart disease. In addition to hypertension (Stage 2), she also has type 2 diabetes and hypercholesterolemia, but is not taking medications for any of these.

At week 4, she normalized her diastolic blood pressure (between 60 and $70 \mathrm{~mm} \mathrm{Hg}$ ) and lost $3 \mathrm{~kg}$ and $14 \mathrm{~cm}$ from her abdomen. By week 8, her diastolic blood pressure remained normal, but her systolic was still elevated. She lost another $6 \mathrm{~kg}$ and her waist circumference decreased another $9 \mathrm{~cm}$.

\begin{tabular}{|c|c|c|c|}
\hline Time & Baseline & Week 4 & Week 8 \\
\hline Morning & & & \\
\hline Blood pressure (mm Hg) & $153 / 84$ & $158 / 72$ & $135 / 55$ \\
\hline Heart rate (BPM*) & 74 & 67 & 65 \\
\hline Evening & & & \\
\hline Blood pressure (mm Hg) & $184 / 92$ & $135 / 63$ & $140 / 55$ \\
\hline Heart rate (BPM) & 63 & 69 & 67 \\
\hline
\end{tabular}

*Beats per minute

Table 10: Changes in blood pressure and pulse rate for RS.

\section{MH}

Mr. MH is a 60-year-old with Stage 2 hypertension, obesity (BMI $34 \mathrm{~kg} / \mathrm{m}^{2}$ ), and a large waist circumference 


\section{Medical Journal of Clinical Trials \& Case Studies}

placing him at high risk for hypertension, heart disease, and type 2 diabetes. He is managed with a beta blocker (Labetalol), losartan (ARB), and clonidine (a centrallyacting alpha-agonist). In addition, he has type 2 diabetes, for which he uses insulin, and has neuropathy and hypercholesterolemia. $\mathrm{MH}$ was not always able to consume the recommended amounts of the nutrient-rich meals and food bars due to recurring epi-gastric pain. He had no change in blood pressure at week 4, but did experience a 6 -kg weight loss with no change in waist circumference. At week 6, he developed diabetic gastric paresis and withdrew from the study at his physician's advice.

\begin{tabular}{|c|c|c|c|}
\hline Time & Baseline & Week 4 & Week 8 \\
\hline Morning & & $\begin{array}{c}\text { Withdrew from } \\
\text { study }\end{array}$ \\
\hline $\begin{array}{c}\text { Blood pressure (mm } \\
\text { Hg) }\end{array}$ & $157 / 90$ & $174 / 86$ & \\
\hline Heart rate (BPM*) & 80 & 70 & \\
\hline $\begin{array}{c}\text { Evening } \\
\begin{array}{c}\text { Blood pressure (mm } \\
\text { Hg) }\end{array}\end{array}$ & $180 / 90$ & $160 / 86$ & \\
\hline Heart rate (BPM) & 80 & 70 & \\
\hline
\end{tabular}

*Beats per minute

Table 11: Changes in blood pressure and pulse rate for $\mathrm{MH}$.

\section{Acknowledgments}

The authors are grateful to Rochelle Ramacher and Adam Kossoff, who managed the participants with a caring nature, and, at the same time, assured excellent compliance with their data entry. Also, we are thankful for the technical support provided by Michael Lambeth. Most importantly, we are grateful to the participants who adhered to the Company's heart-targeted dietary program and faithfully completed the data collection forms.

Conflicts of Interest: Dr. Bell, Ms. Baker, and Mr. Marsland are full time employees of Nutrient, the company that sponsored the study and manufactured the foods used in it.

\section{References}

1. High blood pressure. Centers for Disease Control and Prevention.
2. London GM (2004) Efficacy of indapamide $1.5 \mathrm{mg}$, sustained release, in the lowering of systolic blood pressure. J Hum Hypertens 18(2): S9-S14.

3. Kirland EB, Heincelman M, Kinfe G Bishu, Schumann SO, Schreiner A, et al. (2018) Trends in healthcare expenditures among US adults with hypertension: National estimates, 2003-2014. J Am Heart Assoc 7: e008731.

4. U.S. National Library of Medicine. MedlinePlus. High blood pressure medicines.

5. Blood pressure control. Centers for Disease Control and Prevention.

6. Choosing blood pressure medications. Mayo Clinic.

7. Saneei P, Salehi-Abargouei A, Esmaillzadeh A, Azadbakht L (2014) Influence of Dietary Approaches to Stop Hypertension (DASH) diet on blood pressure: A systematic review and meta-analysis on randomized controlled trials. Nutr Metab Cardiovasc Dis 24(12): 1253-1261.

8. Dietary guidelines for Americans 2015-2020, 8 $^{\text {th }}$ (Edn.).

9. Priceonomics Contributor. How much money do you save by cooking at home.

10. Flannel Guy ROI. Cooking at home vs. eating out.

11. Perez V, Chang ET (2014) Sodium-to-potassium ratio and blood pressure, hypertension and related factors. Adv Nutr 5(6): 712-741.

12. Zhang Z, Cogswell ME, Gillespie C, Fang J, Loustalot F, et al. (2013) Association between usual sodium and potassium intake and blood pressure and hypertension among U.S. adults: NHANES 2005-2010. PLoS ONE 8(10): e75289.

13. Bailey RL, Parker EA, Rhodes DG, Goldman JD, Clemens JC, et al. (2016) Estimating sodium and potassium intakes and their ratio in the American Diet: Data from the 2011-2012 NHANES. J Nutr 146(4): 745-750.

14. Bays HE, Schmitz K, Christian A, Ritchey M, Anderson J, et al. (2012) Raisins and blood pressure: A randomized, controlled trial. ACC Moderated Poster Contributions McCormick Place South, JACC 59(13). 
15. Ueshima H, Stamler J, Elliott P, Chan Q, Brown IJ, et al. (2007) Food omega-3 fatty acid intake of individuals (Total, linolenic acid, long-chain) and their blood pressure INTERMAP Study. Hypertension 50(2): 313319.

16. Bell SJ, Ling PR, Marsland C (2016) Nutrient-Dense, Portion-Controlled Meals and Snacks Promote Weight Loss. J Food Technol Nutr Sci 2(1).

17. Bell SJ, Ling PR, Baker RA, Marsland C (2018) Use of self-reported data to determine the effect of nutrientdense meals on body weight and quality of life. J Nutr Food Sci 8(3): 700.

18. Wing RR, Lang W, Wadden TA, Safford M, Knowler WC, et al. (2011) Benefits of modest weight loss in improving cardiovascular risk factors in overweight and obese individuals with type 2 diabetes. Diabetes Care 2011 34(7): 1481-1486.

19. Pulse (heart rate). National Institutes of Health.

20. Trevisol DJ, Moreira LB, Fuchs FD, Fuchs SC (2012) Health-related quality of life is worse in individuals with hypertension under drug treatment: results of population-based study. J Hum Hypertens 26(6): 374380.

21. Classification of Overweight and Obesity by BMI, Waist Circumference, and Associated Disease Risks. National Heart, Lung, and Blood Institute. 